\title{
Inter-annual changes in the biodiversity and community structure of the macrobenthos in Tees Bay and the Tees estuary, UK, associated with local and regional environmental events
}

\author{
R. M. Warwick ${ }^{1, *}$, C. M. Ashman ${ }^{2}$, A. R. Brown ${ }^{2}$, K. R. Clarke ${ }^{1}$, B. Dowell ${ }^{2}$, B. Hart ${ }^{2}$, \\ R. E. Lewis ${ }^{1,2}$, N. Shillabeer ${ }^{2}$, P. J. Somerfield ${ }^{1}$, J. F. Tapp ${ }^{2}$ \\ ${ }^{1}$ Plymouth Marine Laboratory, Prospect Place, West Hoe, Plymouth PL1 3DH, United Kingdom \\ ${ }^{2}$ AstraZeneca, Brixham Environmental Laboratory, Freshwater Quarry, Brixham TQ5 8BA, United Kingdom
}

\begin{abstract}
Abundances of macrobenthic species were monitored twice yearly (March and September) at 6 locations in Tees Bay, UK, between 1973 and 1996, and once yearly at 4 stations in the outer Tees estuary and 7 stations in the inner estuary between 1980 and 1999. In the Bay, multivariate analysis revealed a serial pattern of community change over years for all areas, but with a major shift in community composition between 1986 and 1988. Inter-annual variability in community composition was significantly greater after 1987 than before 1987 in all areas. Overall, inter-annual variability was greater in areas near the estuary mouth than in areas farther away, although the direction of community change and the timing of the discontinuity were the same in all areas. The serial nature of community change with time was also weaker in the areas close to the estuary mouth. Although there was no clear pattern of change in the number of species present over the sampling period, a dramatic increase in Shannon diversity $\left(H^{\prime}\right)$ occurred after 1987, due to an increase in evenness that resulted from the reduction of a few previously dominant species, notably the small polychaete Spiophanes bombyx. Although biodiversity measures describing the taxonomic breadth of the species assemblages also showed a marked step change in 1987, this was one of reduced diversity, with average taxonomic distinctness $\left(\Delta^{+}\right)$decreasing and the variation in taxonomic distinctness $\left(\Lambda^{+}\right)$increasing. These abrupt, detrimental changes coincided with a well-documented change in a variety of components of the North Sea ecosystem during the same period. Traditional species diversity measures, such as $H^{\prime}$, therefore gave a false impression of improving environmental quality over this period: given that the average taxonomic spread was reduced, certain taxa were under-represented with respect to others, and community composition as measured by a multivariate stability index (MSI) became less stable. $H^{\prime}$ also failed to distinguish putatively impacted areas close to the estuary mouth compared with those more distant, despite clear differences in $\Delta^{+}, \Lambda^{+}$, and in community stability (MSI). Overall patterns of biodiversity and community composition in the Bay have thus been affected temporally by regional changes in the North Sea ecosystem, and spatially by the effects of the estuarine outflow. In the estuary itself, multivariate analysis also revealed a serial pattern of community change, with a major shift in composition in 1994 in both the outer and inner estuary which coincided with the construction of a barrage in the estuary. The numbers of both individuals and species began to increase at this time in the outer estuary. $H^{\prime}$ showed no obvious changes over the period, but in the outer estuary a step change in $\Delta^{+}$and $\Lambda^{+}$occurred at the same time as that in the Bay. However, the direction of change was the reverse of that in the Bay, suggesting an improvement in environmental quality or a shift to more saline conditions.
\end{abstract}

KEY WORDS: Time series $\cdot$ Ecosystem change $\cdot$ North Sea $\cdot$ Multivariate analysis $\cdot$ Species diversity Taxonomic distinctness $\cdot$ Inter-annual variability $\cdot$ Environmental stress 


\section{INTRODUCTION}

Temporal and spatial changes in marine benthic assemblages have usually been explained in terms of local environmental changes, either anthropogenic or natural. However, recently it has been suggested that more global (oceanic) influences may have been underestimated, and these have been invoked to explain sudden abrupt changes observed in the North Sea and elsewhere (Lindeboom et al. 1995, Reid et al. 2001b). In this paper, we analyse data from a time series of samples in Tees Bay and the Tees estuary, UK, and relate the changes observed to potential regional and local environmental influences. We place particular emphasis on methods of analysis that enable us to put a value judgement on the observed changes, for example whether they represent environmental deterioration or improvement.

\section{Environmental changes in the North Sea}

During the period of this study, a major change in the North Sea ecosystem occurred which was of such sufficient magnitude to have been termed a 'regime shift' (Reid et al. 2001a, Reid \& Edwards in press). All trophic levels in the system were affected. A step change in chlorophyll levels occurred after 1987, the seasonal pattern of spring and autumn peaks that had occurred since at least 1949 switching to continuously high levels between April and October, with the winter months showing a $>90 \%$ rise in colour intensity, as measured by the Continuous Plankton Recorder. Individual species of both phytoplankton and zooplankton also showed marked changes in abundance at this time and catches of the western stock of horse mackerel greatly increased. Changes in the distribution of herring (Corten \& van de Kamp 1992) and a substantial increase in the biomass of the macrobenthos off the Freisian Islands (Kröncke et al. 1998) also occurred. Coinciding with this regime-shift, a number of warmwater species have increased in the North Sea, including the Mediterranean red mullet, the subtropical cladoceran Penilia avirostris and the doliolid Doliolum nationalis. The timing of the regime shift also coincided with the seal epidemic and the toxic Chrysochromulina bloom (Reid \& Edwards in press). Many of these changes occurred throughout the North Sea and were also reflected in changes to the west of the British Isles and in oceanic waters (Vuorinen et al. 1998, Edwards et al. 2001), and are therefore regarded as the consequences of a major hydroclimatic event rather than of local events such as eutrophication. Sea surface temperature, the total heat content and modelled advections of warm oceanic water into the North Sea also increased at about the same time (Reid \& Edwards in press), as did levels of nutrients in the Skagerrak, while levels of oxygen declined (Dahl \& Danielssen 1992). In the Helgoland Roads, an increase in Si and the $\mathrm{NO}_{3}: \mathrm{PO}_{4}$ ratio occurred in 1987, which was associated with an abrupt rise in the flagellate:diatom ratio (Hickel et al. 1996). It is perhaps significant to note that the timing of this regime shift approximates to the beginning of the most consistently positive phase of the North Atlantic Oscillation (NAO) in > 150 yr (Dickson \& Turrell 2000): a positive NAO index causes higher temperatures in the North Sea (Becker \& Pauly 1996). Another potential cause of the regime shift, perhaps driven by the NAO, is that the North Sea experienced a series of cold winters prior to 1988 , followed by particularly mild winters and an increase in both salinity and storminess (Becker et al. 1997, Ducrotoy et al. 2000). River discharges have also decreased, with low salinities in the 1970s and 1980s, and higher values from 1989 to 1995, reduced run-off leading to increased inflow of Atlantic water to the North Sea (Prandle et al. 1997). The causes of the regime shift are still under debate, but its widespread symptoms are unequivocal.

In the North Sea, there are indications that certain major taxa are decreasing in abundance at the expense of others in response to both natural variability and anthropogenic pressures (North Sea Task Force 1993). For example, in the Wadden Sea, polychaetes were seen to increase at the expense of other major taxa (Reise 1982). This suggests that major changes in biodiversity may occur that may not be detectable as a net change in species richness or evenness. If we continue to use these traditional indices for monitoring purposes, changes in biodiversity may go undetected until a very advanced stage of environmental degradation is reached.

\section{Environmental changes in the Tees estuary}

The Tees estuary was used as a depository for industrial and domestic effluents for much of the 20th century. During the latter half of that period, there were major changes to the bathymetry of the system due to extensive reclamation of the mudflats, the construction of tide training walls and dredging of the main channel. The discharges to the relatively confined tidal waters of the estuary resulted in gross depletion of dissolved oxygen and a consequent loss of marine and estuarine fauna (Shillabeer \& Tapp 1990). In 1994, water quality was further influenced by the commencement of the construction of a barrage that effectively halved the length of the tidal estuary. This barrier acts as a weir, preventing the incursion of saline water and forming a non-tidal freshwater river on its upstream side. More recently, water quality was also affected by the closure of the sewage treatment works 
at Portrack and Cargo Fleet, in 1997 and 1998, respectively, and also by the transfer of the waste to a new treatment plant at Bran Sands on the lower estuary.

Major surveys of the water quality of the Tees estuary were undertaken at 5 yearly intervals between 1970 and 1995. The variation in the total biological oxygen demand (BOD) input to the Tees estuary over the period 1970 to 1995 illustrates the influence of the economy and environmental controls on discharges (Fig. 1a). In 1970, the chemical industry on Teesside was thriving and pollution controls were relatively lax. However, this situation changed when in 1973 the price of oil, the raw material for many of the products, escalated. The development of North Sea oil and the pipeline link between Teesside and the 'Ekofisk' field, together with new chemical products, saw discharges to the estuary rise slightly in 1985. Subsequent tightened controls on discharges and the introduction of improved treatment measures resulted in reductions in both BOD and ammonia loads. From 1985 onwards, oxygen levels remained very low, particularly in the near bottom waters (Fig. 1b). Plots of maximum ammonia concentrations over the period 1975 to 1995, corrected for the influence of freshwater flow, indicate that this parameter reached a peak around 1985 and then showed a marked decline (Fig. 1c).

Contamination in the lower estuary is generally a surface phenomenon. This situation arises because the major industrial effluent and sewage discharges are released with large volumes of fresh water. This results in a relatively buoyant waste field that tends to be advected seawards by the ebbing tide and ultimately released from the confines of the estuary into the open waters of Tees Bay. Simple modelling studies have estimated how far from the estuary mouth these wastes will travel before mixing to the seabed is complete (Lewis 1990, 1992). It was found that on tides of neap range, the minimum dilution at the seabed for pollutants emanating from the estuary would occur about $1.5 \mathrm{~km}$ from the estuary mouth, which approximately corresponds to benthic fauna sampling area 3 (Teesmouth) (Fig. 2). On spring tides, the region of minimum dilution would be some $4.0 \mathrm{~km}$ from the estuary mouth, assuming the same rate of vertical mixing; this corresponds to benthic fauna sampling area 2 (Longscar). Total macrobenthic biomass and the rate of growth of Fabulina fabula have provided evidence of ecological impact on marine life exposed to the outflowing estuary waters at both Areas 2 and 3 (Shillabeer \& Tapp 1990).

\section{MATERIALS AND METHODS}

Field sampling and sample processing. Surveys of the soft-bottom macrobenthic fauna communities in
Tees Bay and the Tees estuary were primarily designed to assess the extent of the ecological impact due to aqueous discharges from the numerous petrochemical industries on Teesside. The use of consistent sampling and analytical protocols has enabled long-term temporal trends in community ecology to be elucidated alongside reductions in pollution loads (Shillabeer \& Tapp 1990). The first survey in Tees Bay was completed in September 1973, the second survey in March 1974. These surveys, comprising Areas 0 to 6, continued on a biannual basis until 1991, after which the March surveys were suspended to reduce monitoring
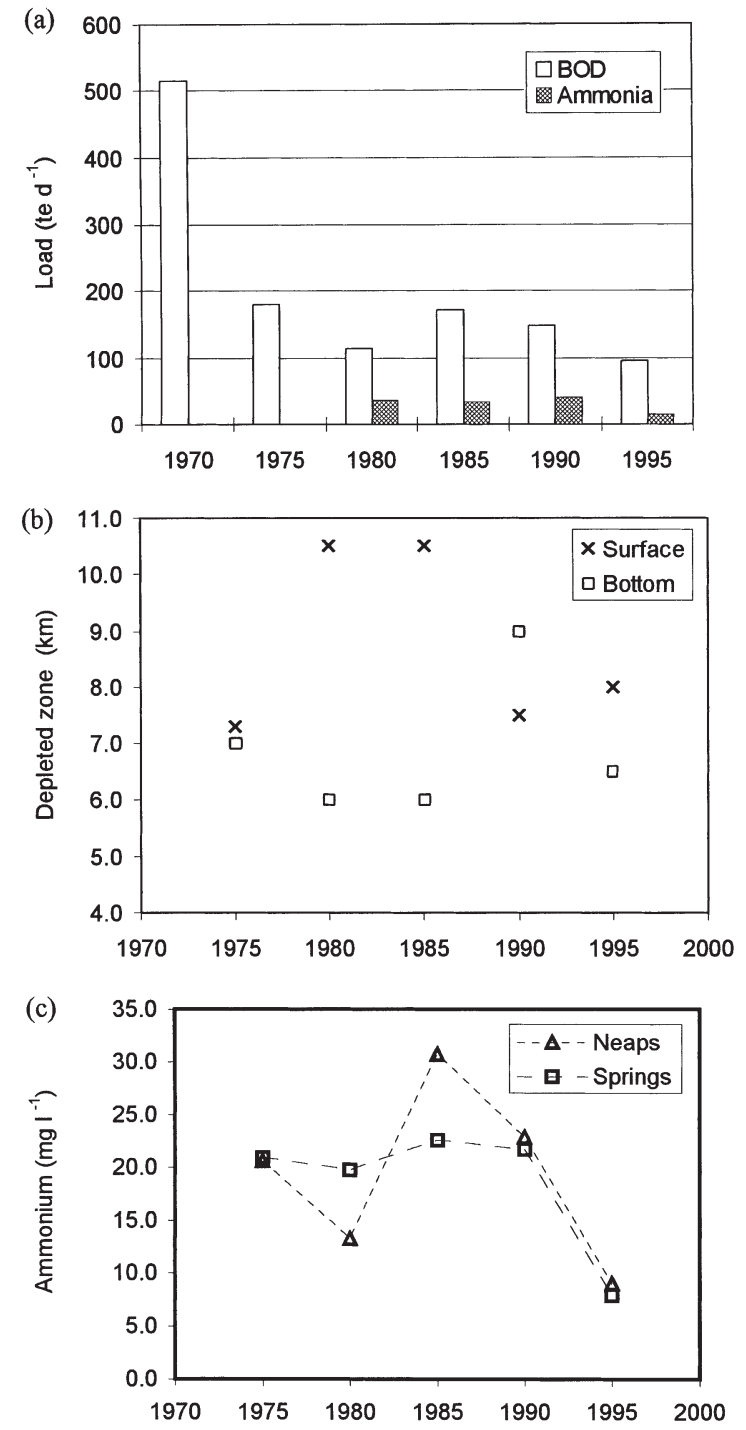

Fig. 1. (a) Variation in total biological oxygen demand (BOD) and ammonia loads (te: tonnes) in the Tees estuary over the period from 1970 to 1995 (note that ammonia was not measured in 1970 and 1975). (b) Changes in length of the zone with depleted dissolved oxygen, taken as less than $1.0 \mathrm{mg} \mathrm{l}^{-1}$ (c) Changes in maximum ammonia concentrations, after correction for freshwater flow variations, over the period from 1975 to 1995 


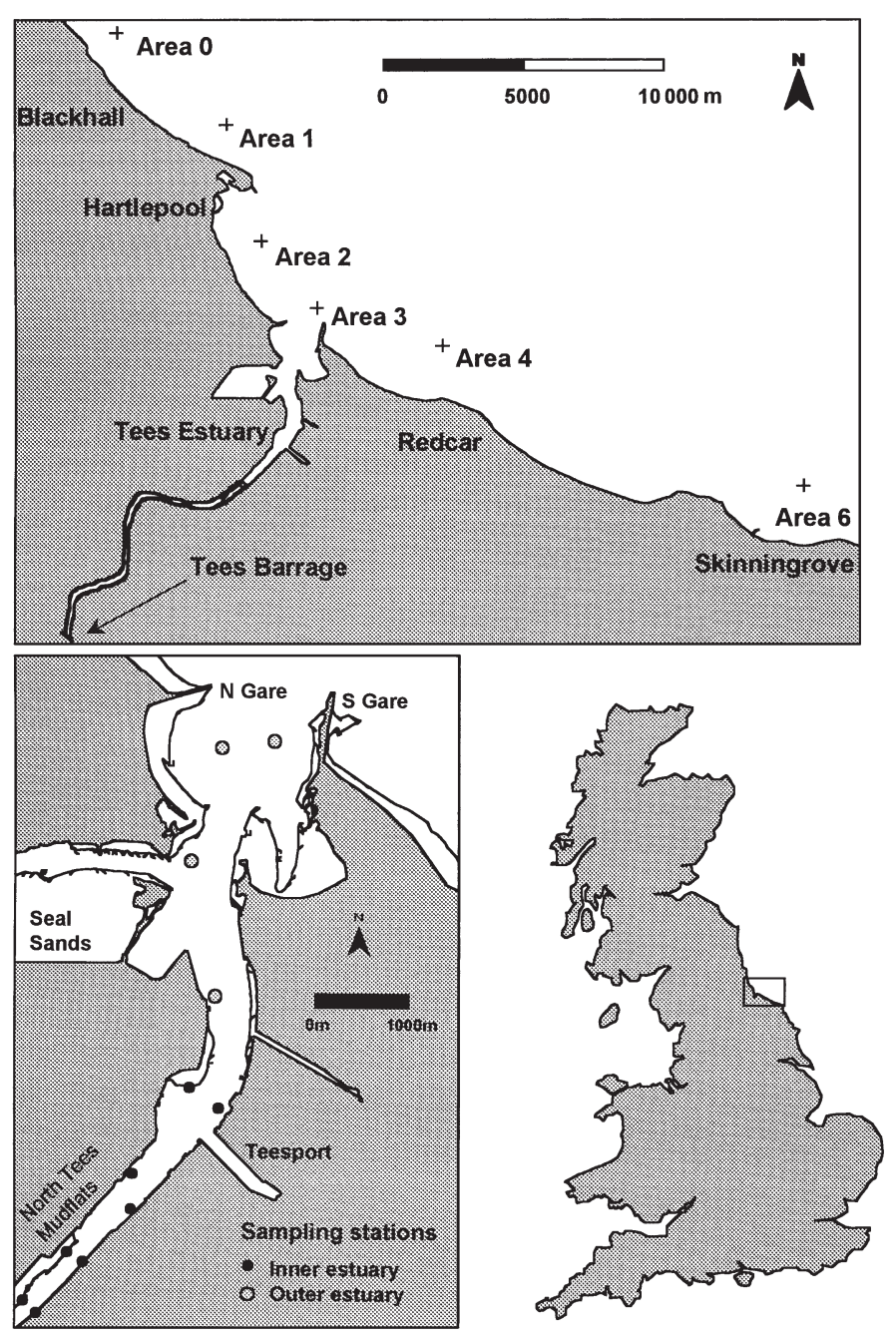

Fig. 2. Map of the Tees coastal region, UK, showing the 2 sampling areas in the Tees estuary (inner and outer) and the 6 sampling areas in Tees Bay $(0,1,2,3,4,6)$. Data for each year and season (March and September) are averaged from several sampling sites within each Tees Bay area (typically 3) and several replicates within each site (typically 5), so that each value, for the $24 \mathrm{yr}$ time series, is based on a substantial body of observational evidence

costs. A further cost saving was made after 1994 when sampling was restricted to Areas 1 to 4 .

Sampling in Tees Bay: During the monitoring periods, March 1974 to 1991 and September 1973 to 1994, sampling was conducted in 6 discrete survey areas, namely Areas 0, 1, 2, 3, 4 and 6 (Fig. 2). Water depths ranged from 15 to $22 \mathrm{~m}$ and sediments were very uniform, consisting predominately of very fine sand. Area 5 (not depicted) was also sampled over the same period but has been excluded from this investigation because it is shallow ( $5 \mathrm{~m}$ ) and also it is close to the Langbaurgh sewer outfall. In September 1995 and 1996 sampling was restricted to 4 areas (Areas 1 to 4 ), after which Tees Bay surveys were halted. The majority of stations within each survey area were sampled in replicates of 5, while others were sampled individually. Station positions were fixed using the 'Decca Navigator' system and sampling was performed prior to 1985 using a $0.1 \mathrm{~m}^{2}$ Smith-McIntyre grab and subsequently using a $0.1 \mathrm{~m}^{2}$ Day grab. These 2 grab samplers produced comparable results when used on Tees Bay sediments (Shillabeer 1993). Sample processing involved taking a $20 \mathrm{~mm}$ diameter core of sediment from each grab sample for particle size analysis, after which the remainder was washed through a $1 \mathrm{~mm}$ mesh sieve. The retained material was then preserved with $4 \%$ formalin in seawater and Rose Bengal was used as a vital stain, to facilitate the sorting of fauna during sample analysis.

Sampling in Tees estuary: A series of subtidal stations were sampled consistently in the Tees estuary between 1980 and 1999 using a $0.1 \mathrm{~m}^{2}$ Day grab (Fig. 2). Sample positions corresponded to those of fixed navigation buoys at the edge of the main, dredged channel. In the absence of sample replication, these stations were conveniently grouped into Areas A and B representing the outer Tees estuary (Teesport to the Gares) and the inner estuary (Teesport to north Tees mudflats). Samples were processed in the same way as those from Tees Bay.

Sample analysis: Benthic fauna were enumerated and identified to the lowest possible taxonomic level (normally species). In Tees Bay, both the total macrobenthic biomass and the biomass of the dominant fauna families in each sample were determined. Between 1973 and 1990 biomass was determined as ash-free dry wt (Crisp 1984) and between 1993 and 1996 as blotted wet wt. For consistency, only the 1973 to 1990 data are presented here.

Data analysis. Univariate indices: In this study, we have compared more 'traditional' indices with more recently developed biodiversty measures that describe the taxonomic spread of species (Warwick \& Clarke 2001). The former include the number of species per unit area $(S)$, the total abundance of individuals $(A)$, the total biomass $(B)$, Shannon diversity $\left(H^{\prime}\right)$ and Pielou's evenness $\left(J^{\prime}\right)$, the last 2 indices using $\log _{\mathrm{e}}$ in their formulation.

Warwick \& Clarke (1995) have defined taxonomic indices in terms of average 'distance apart' of all pairs of individuals (or species) in a sample by tracing these distances through a taxonomic tree. 'Average taxonomic diversity' $(\Delta)$ is simply the average path length between every pair of individuals in a sample (Warwick \& Clarke 1995) and is defined as:

$$
\Delta=\left[\Sigma \Sigma_{i<j} \omega_{i j} X_{i} X_{j}\right] /[n(n-1) / 2]
$$


where $x_{i}(i=1, \ldots, \mathrm{s})$ denotes the abundance of the $i$ th species, $n\left(=\Sigma_{i} X_{i}\right)$ is the total number of individuals in the sample, $\omega_{i j}$ is the 'distinctness weight' given to the path length linking species $i$ and $j$ in the hierarchical classification, and the double summations are over all pairs of species $i$ and $j$. (Note that the path length between 2 individuals of the same species is set to 0.) A second index, 'average taxonomic distinctness (AvTD)', $\Delta^{*}$ (Warwick \& Clarke 1995), is modified to remove some of the dependence of $\Delta$ on the species abundance distribution represented by the $\left\{x_{i}\right\}: \Delta$ is divided by its value when the hierarchical classification collapses to the special case of all species belonging to a single genus. The resulting ratio, $\Delta^{*}$, is then more nearly a function of pure taxonomic relatedness of individuals. The algebraic definition of average taxonomic distinctness is:

$$
\Delta^{*}=\left[\Sigma \Sigma_{i<j} \omega_{i j} X_{i} x_{j}\right] /\left[\Sigma \Sigma_{i<j} x_{i} x_{j}\right]
$$

A special case is the use only of presence/absence information for each species (i.e. simple species lists), when $\Delta$ and $\Delta^{*}$ reduce to the same statistic, namely:

$$
\Delta^{+}=\left[\Sigma \Sigma_{i<j} \omega_{i j}\right] /[s(s-1) / 2]
$$

where $s$ is the number of species present and, for the double summation, $i$ and $j$ range over these $s$ species. The mean values of all 3 of these indices have been shown to be independent of sample size, i.e. the number of individuals in the case of $\Delta$ and $\Delta^{*}$, and the number of species in the case of $\Delta^{+}$(Clarke \& Warwick 1998), which implies that $\Delta^{+}$in particular can be compared across studies with differing and uncontrolled degrees of sampling effort.

Another aspect of the taxonomic structure recently explored by Clarke \& Warwick (2001) is the 'evenness' of the distribution of taxa across the hierarchical taxonomic tree. A completely even distribution might occur in the hypothetical situation where all path lengths between species were equal, and an uneven distribution where the path lengths were very unequal (e.g. some very species-rich genera and other species being the sole representatives of their phylum). Such a difference in structure is reflected in variability of the full set of pairwise distinctness weights making up the average. Variation in taxonomic distinctness (VarTD, denoted by $\Lambda^{+}$) is therefore defined as:

$\Lambda^{+}=\left[\Sigma \Sigma_{i<j}\left(\omega_{i j}-\bar{\omega}\right)^{2}\right] /[s(s-1) / 2]=\left[\left\{\Sigma \Sigma_{i<j} \omega_{i j}{ }^{2}\right\} /\{s(s-1) / 2\}\right]-\bar{\omega}^{2}$ where:

$$
\bar{\omega}=\left\{\Sigma \Sigma_{i<j} \omega_{i j}\right\} /\{s(s-1) / 2\} \equiv \Delta^{+}
$$

Clarke \& Warwick (2001) have shown that VarTD has the same desirable sampling properties as AvTD, primarily a lack of dependence of its mean value on the sample size (except for rather small samples where it has a slight negative bias).
For all 4 of these indices, we have assumed equal step-lengths between each successive taxonomic level, setting the path length $\omega$ to 100 for 2 species connected at the highest (taxonomically coarsest) possible level (Clarke \& Warwick 1999). We have used 6 taxonomic levels: species, genus, family, order, class, phylum, so that the weights are $\omega=16.7$ (species in the same genus), 33.3 (same family but different genera), 50 (same order but different families), 66.7 (same class but different orders), 83.3 (same phylum but different classes) and 100 (different phyla), respectively.

Multivariate analysis: Inter-annual changes in community composition have been visualised from nonmetric multidimensional scaling (MDS) plots based on triangular matrices of Bray-Curtis similaries using 4th root transformed species abundance data. Whilst these plots indicate the relative magnitude of community change between years, and the relative directions of change, they do not in themselves enable us to place a value judgement on this change, such as whether the conditions are improving, worsening or remaining the same. Two multivariate measures of community stress have been applied here, the index of multivariate dispersion (IMD, Warwick \& Clarke 1993) and the index of multivariate seriation (IMS, Clarke et al. 1993). The IMD is a measure of the increase in variability among replicate samples from perturbed versus control situations and has previously been applied only to treatment or spatial differences, but is used here as a measure of inter-annual variability or community stability, i.e. a multivariate stability index MSI. The index contrasts the average rank of the dissimilarities among one set of samples (pre-1987) with the average rank among the other set (post-1987), having re-ranked the full triangular matrix ignoring all between-group dissimilarities. It is standardised to have a maximum value of +1 when all dissimilarities among the first group of samples are higher than any dissimilarities among the second group, and -1 when the reverse is true. Values near 0 imply no difference between the 2 groups. The IMS is a measure of the degree to which community change conforms to a perfectly linear sequence. It is the Spearman rank correlation $(\rho)$ between the biological similarities among samples and the similarity matrix that would result from the interpoint distances of the same number of samples equally spaced along a straight line. Spatial breakdown of the seriation pattern has been suggested as a measure of community stress, and here we examine its application to inter-annual changes in community composition. The underlying premise here is that community composition in any one year is likely to be determined by biological mechanisms such as reproduction and species interactions during the preceding year, resulting in a serial pattern of inter-annual community change. 

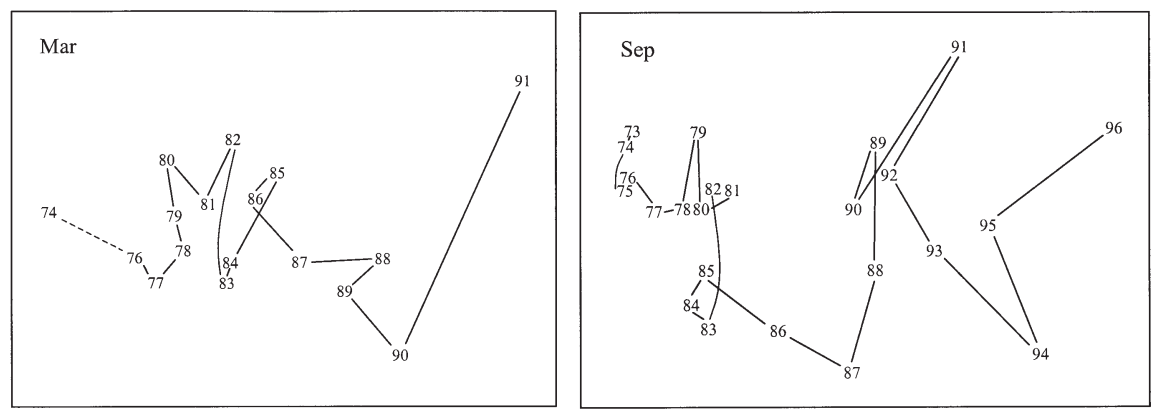

Fig. 3. Non-metric multidimensional scaling (MDS) plots of Tees Bay macrofaunal assemblages for each of 17 yr (1974 to 1991, March sampling, top plot) and $24 \mathrm{yr}$ (1973 to 1996, September sampling, bottom plot). Points are based on the averaged abundance for each species over all 6 areas $(0$ to 4,6$)$, then subjected to 4 th root transform prior to calculation of Bray-Curtis similarities. MDS stress = 0.12 in both cases

Disturbance will introduce a more stochastic element and result in a breakdown of this seriation.

\section{RESULTS}

\section{Tees Bay}

Averaged over the whole Bay, the multivariate ordinations showed similar patterns of inter-annual community change in both March and September (Fig. 3).
From the beginning of the sampling period until 1986, there was an approximately serial pattern of community change with relatively small changes between years (except from 1982 to 1983). In 1987 through to 1988, there was a major shift in community composition, and from 1988 onwards the changes between years increased, although the serial pattern of change was maintained. MDS plots for the individual areas in the Bay were very similar to one another (Fig. 4 shows the September data only, but in March the patterns were also consistent). The individual plots each reflect the overall pattern in terms of the seriation, timing of the step change, and increased variability (on average) post1987. The latter is reflected in the values of the comparative MSI for each area in both March and September (Table 1). In each case, the inter-annual variability is higher post-1987 than pre-1987, giving a negative value for the MSI, thus rejecting the null hypothesis of no variability differences between time periods ( 6 negatives from 6 trials give a significance level of $1.5 \%$ in a sign test). In addition, the correlation of the multivariate pattern of change with a perfectly linear sequence (IMS expressed as the Spearman rank correlation coefficient, $\rho$ ) is lower in Areas 2 and 3, closest to the

Fig. 4. Multidimensional scaling (MDS) ordination plots of Tees Bay assemblages, separately for each of the 6 sampling areas $(0,1$, $2,3,4,6)$, over the 24 yr of September sampling (22 yr in Area 0). Points are based on 4th root transformed abundances and BrayCurtis similarities. Values of the seriation coefficient (a Spearman correlation, $\rho$, between faunal similarities and equal-stepped time points in a linear sequence) are given for each ordination. MDS stress $=0.16,0.14$, $0.18,0.19,0.13,0.14$ respectively 
Table 1. Values of multivariate dispersion prior to and after 1987, separately for March and September samples, based on 4 th root species abundance data and Bray-Curtis similarities, and the resulting multivariate stability index (MSI)

\begin{tabular}{|lcccc|}
\hline Month & Area & Pre-1987 & Post-1987 & MSI \\
\hline Mar & All & 0.96 & 1.43 & -0.47 \\
& 0 & 0.99 & 1.14 & -0.15 \\
& 1 & 0.99 & 1.08 & -0.09 \\
& 2 & 0.97 & 1.30 & -0.33 \\
& 3 & 0.97 & 1.32 & -0.35 \\
& 4 & 0.98 & 1.26 & -0.28 \\
Sep & 6 & 0.96 & 1.42 & -0.46 \\
& All & 0.86 & 1.37 & -0.51 \\
& 0 & 0.97 & 1.12 & -0.15 \\
& 1 & 0.83 & 1.43 & -0.60 \\
& 2 & 0.91 & 1.24 & -0.33 \\
& 3 & 0.90 & 1.26 & -0.36 \\
& 4 & 0.81 & 1.48 & -0.67 \\
& 6 & 0.96 & 1.11 & -0.15 \\
\hline
\end{tabular}

estuary mouth, than in Areas 0, 1, 4 and 6, which are farther away (Fig. 4). Since the orientation and scaling of the MDS plots in Fig. 4 is arbitrary, plots of several stations combined have also been made to examine whether the direction and magnitude of changes are comparable across stations. Fig. 5 is an example comparing Areas 0 and 3 by combining the data from these 2 locations in a single analysis, and illustrates the general conclusion that the direction of community change and timing of the discontinuity is the same in all cases. However, the overall magnitude of change differs between areas (greater inter-annual variability in Area 3 close to the estuary mouth).

Although the number of species per unit area averaged over the whole Bay fluctuated from year to year, there was no clear long-term trend in either the March or September data (Figs. 6 \& 7). The situation was similar for total abundance, although there appeared to be a gradual decline throughout the sampling period in the September data. Total biomass, determined in March only, showed no clear time trend of change, although high values were found in some years in the middle of the sampling period. A step increase in Shannon diversity $\left(H^{\prime}\right)$ occurred between 1987 and 1988, although this was most obvi-

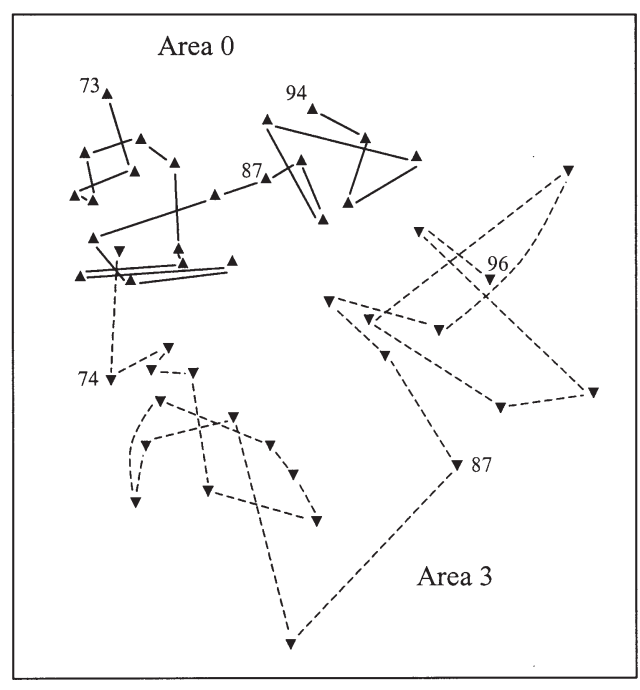

Fig. 5. Combined multidimensional scaling (MDS) ordination plot of Tees Bay assemblages, in September samples, for the 2 areas, Areas 0 and 3, which have respectively the least and greatest measures of multivariate dispersion over the years with the data treated as in Fig. 4. MDS stress $=0.21$

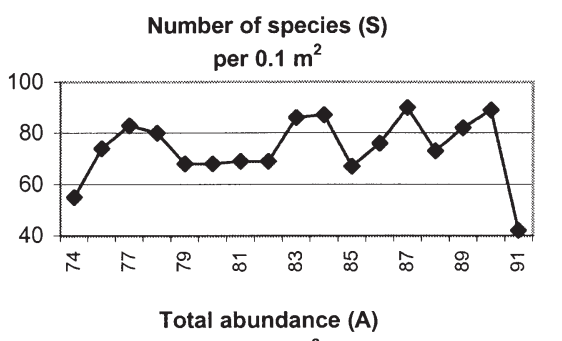

per $0.1 \mathrm{~m}^{2}$

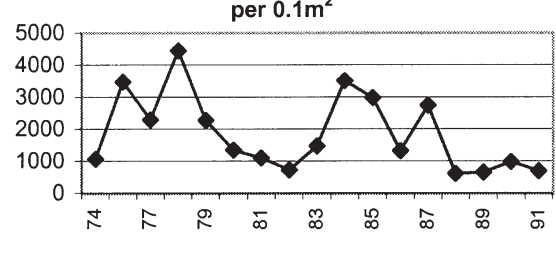

Shannon species diversity ( $H^{\prime}$ using $\log _{\mathrm{e}}$ )
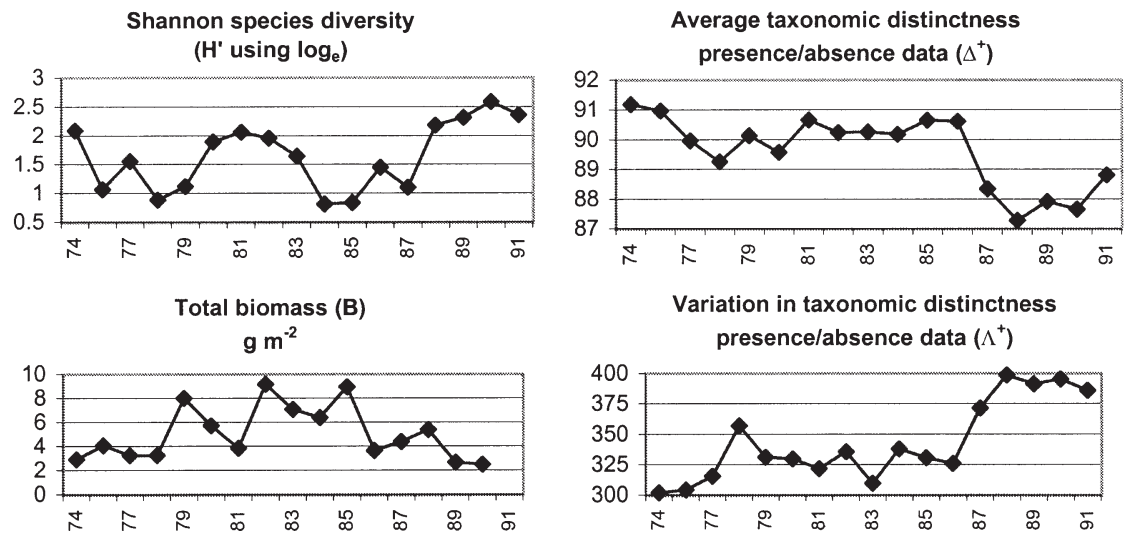

Fig. 6. Time series (1974 to 1991) of various indices for the March macrofaunal samples, averaged over all areas in Tees Bay. Left column: standard univariate species, abundance, biomass and Shannon diversity indices; right column: biodiversity measures based on relatedness of species within an assemblage. Note that there are no data for 1975 

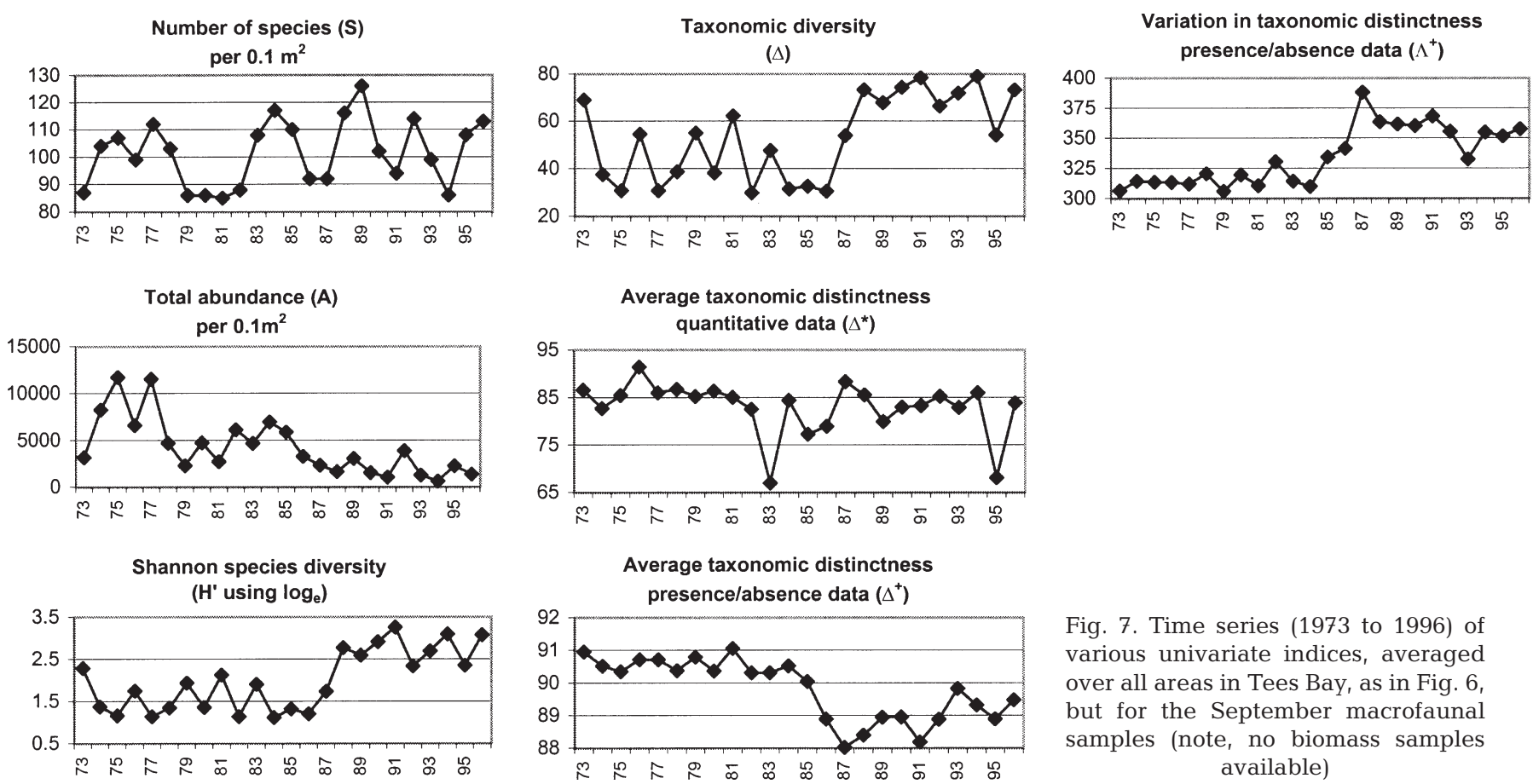

Fig. 7. Time series (1973 to 1996) of various univariate indices, averaged over all areas in Tees Bay, as in Fig. 6, but for the September macrofaunal samples (note, no biomass samples available)

ous in September because there was also a period of relatively high diversity between 1980 and 1983 in the March data. Changes in evenness $\left(J^{\prime}\right.$, not illustrated) and taxonomic diversity $(\Delta)$ closely mirrored changes in $H^{\prime}$, but taxonomic distinctness, based on quantitative species abundance data $\left(\Delta^{*}\right)$, remained virtually constant. A very clear step decrease in average taxonomic distinctness based on presence/absence data $\left(\Delta^{+}\right)$and an increase in the variation in taxonomic distinctness $\left(\Lambda^{+}\right)$were evident, starting in March 1987 and completed by September 1987. Patterns of change in these univariate measures over time were consistent between areas, and the values for $\Delta^{+}$ are shown as an example in Fig. 8. This figure shows that in the individual areas, changes in $\Delta^{+}$were apparent by 1986, and in Area 6 as early as 1985 . Values of $S, B, \Delta, \Delta^{*}$ and $\Delta^{+}$were consistently lower in Areas 2 and 3, close to the estuary mouth, than in Areas 0, 1, 4 and 6 farther away, and $\Lambda^{+}$was consistently higher (Fig. 9). $H^{\prime}$ and total abundance $(A)$ failed to distinguish consistently between the proximal and distant areas.
A dramatic order of magnitude reduction in the abundance of the polychaete Spiophanes bombyx was mainly responsible for the differences in community
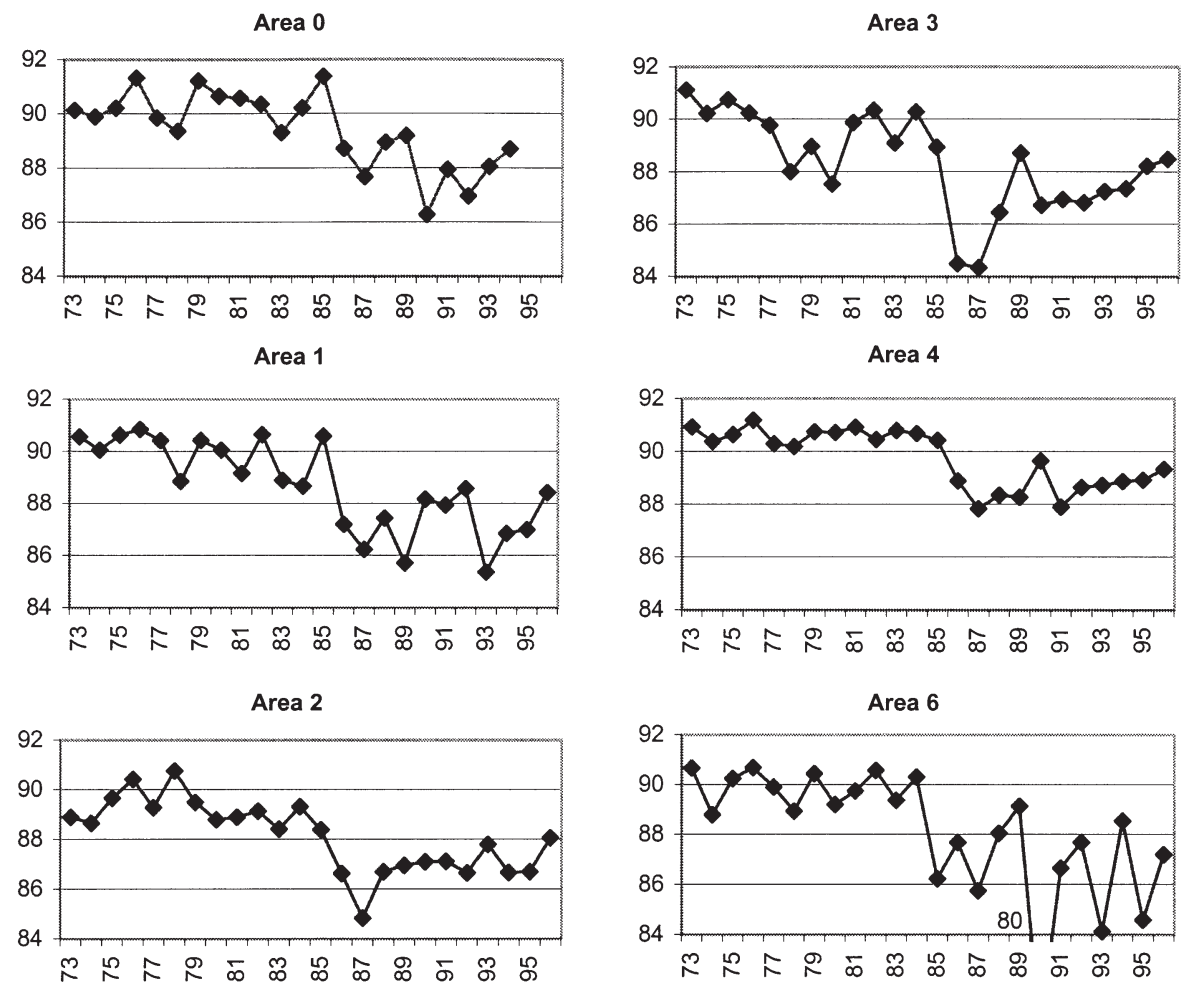

Fig. 8. Time series (1973 to 1996) of average taxonomic distinctness $\left(\Delta^{+}\right)$, based only on presence/absence data, for September macrofaunal samples from the 6 separate areas of Tees Bay $(0$ to 4,6$)$ 
composition pre- and post-1987, in an analysis based primarily on the dominant taxa, i.e. using untransformed abundances (Table 2). Other species that decreased included the bivalve Nucula nitidosa, the polychaetes Nephtys hombergii, Owenia fusiformis, Polydora sp. and Spio filicornis, and the crustaceans Diastylis bradyi and Ampelisca brevicornis. Other species correspondingly increased over this period, including the bivalves Fabulina fabula, Chamelea gallina and Abra alba, and the polychaetes Magelona mirabilis and Chaetozone setosa. The dramatic reduction in Spiophanes bombyx, which was highly dominant prior to 1987 , resulted in the step increase in evenness and hence $H^{\prime}$, the species richness component of this latter measure playing no part.

\section{Tees estuary}

MDS plots for outer and inner estuary (all sites combined) also showed a serial pattern of community change, but in both cases a major discontinuity or step change (left to right on the MDS map) was found in 1994 (Fig. 10). The correlation with a perfectly serial change (based on a 4th root abundance transformation prior to computation of BrayCurtis similarities) was slightly stronger
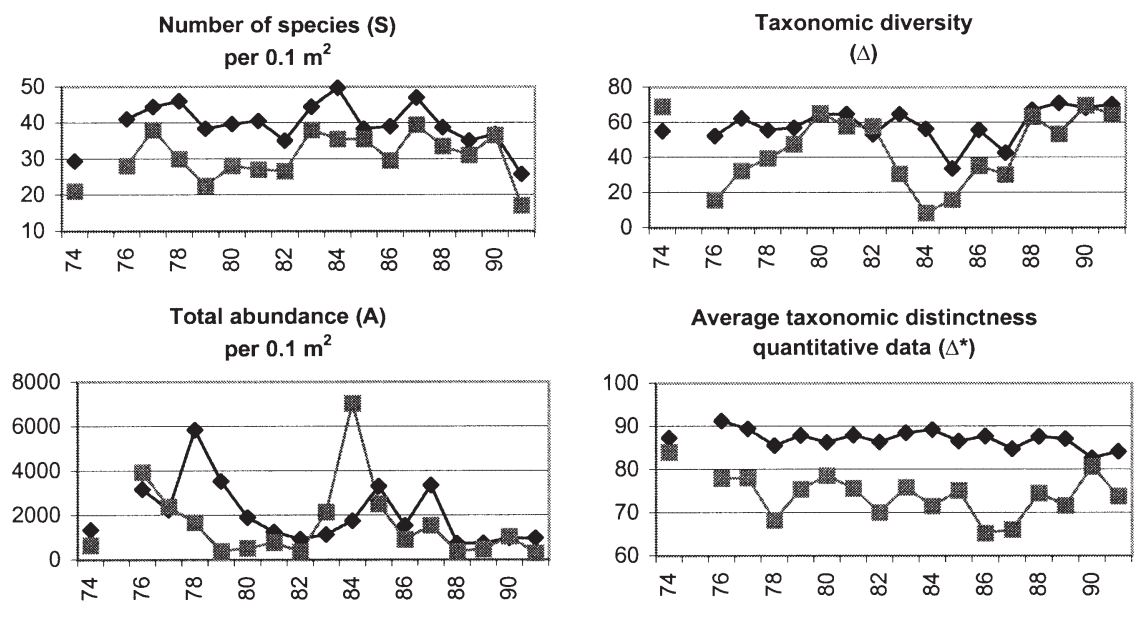
quantitative data $\left(\Delta^{*}\right)$

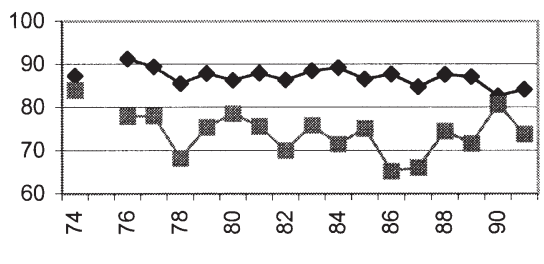

Average taxonomic distinctness presence/absence data $\left(\Delta^{+}\right)$

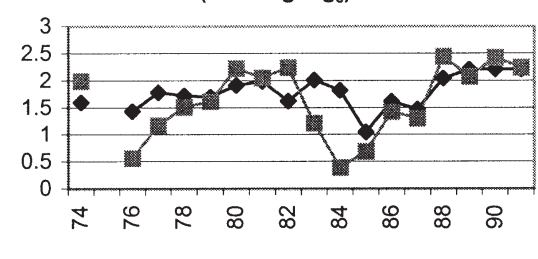

Total biomass (B) $\mathrm{g} \mathrm{m}^{-2}$

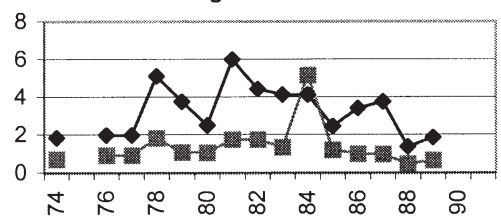

Variation in taxonomic distinctness presence/absence data $\left(\Lambda^{+}\right)$

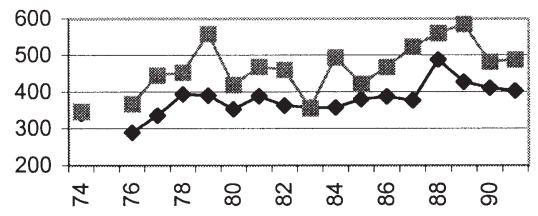

Fig. 9. Times series (1974 to 1991) of univariate indices for March macrofaunal samples, as in Fig. 6, but averaged over 2 groups of areas in Tees Bay, Areas 0, 1, 4,6 ( and black lines), and Areas 2, 3 ( $\mathbf{a}$ and dark grey lines), respectively representing conditions distant from, and within the influence of, the plume from the Tees estuary
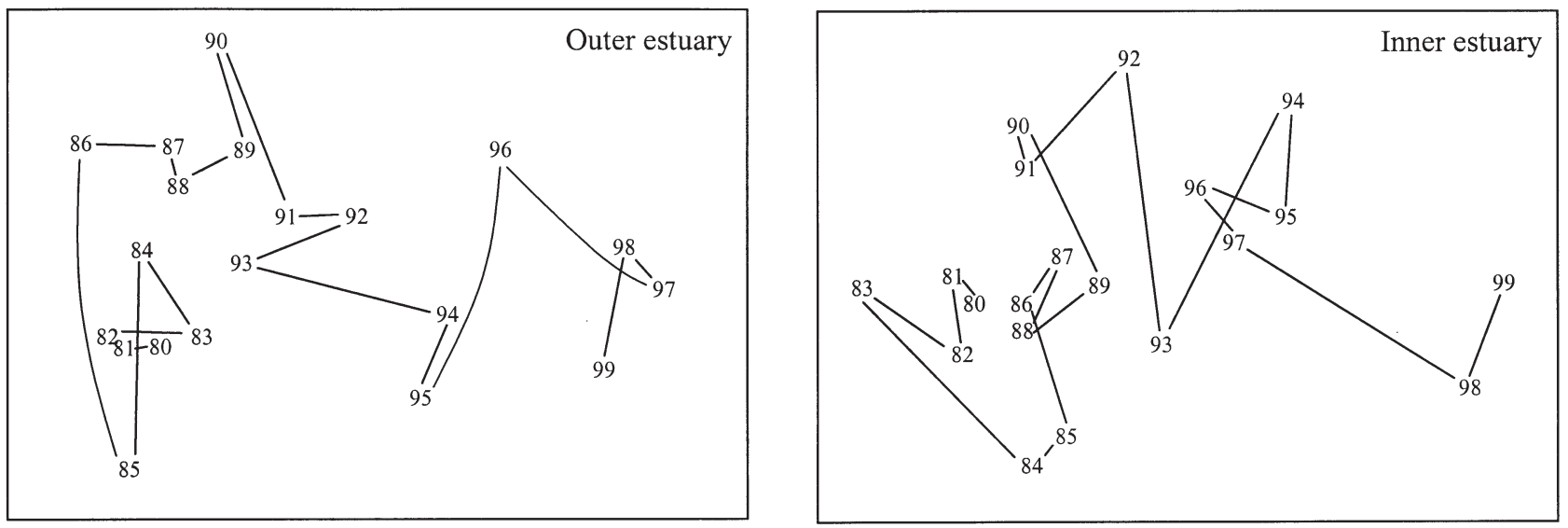

Fig. 10. Multidimensional scaling (MDS) ordination plots from 1980 to 1999, of macrofaunal assemblages from the Tees estuary, sampled in September. Samples are averaged over all sites in the outer (top plot) and inner estuary (bottom plot), before a 4th root transformation is taken and Bray-Curtis similarities are calculated. (MDS stress $=0.14,0.15$ respectively) 
Table 2. The 10 taxa most responsible for the differences in species composition in Tees Bay pre-1987 and post-1987, listed in order of importance of their contribution to the average Bray-Curtis dissimilarity between these periods (based on untransformed abundances $0.1 \mathrm{~m}^{-2}$ )

\begin{tabular}{|lrr|}
\hline Species & $\begin{array}{c}\text { Average } \\
\text { abundance } \\
\text { pre-1987 }\end{array}$ & $\begin{array}{c}\text { Average } \\
\text { abundance } \\
\text { post-1987 }\end{array}$ \\
\hline Mar & & \\
Spiophanes bombyx & 1440 & 176 \\
Nucula nitidosa & 198 & 155 \\
Fabulina fabula & 65 & 105 \\
Nephtys hombergii & 57 & 19 \\
Nephtys sp. (juvenile) & 8 & 44 \\
Chamelea gallina & 19 & 41 \\
Magelona mirabilis & 40 & 62 \\
Owenia fusiformis & 24 & 8 \\
Polychaete larvae & 12 & 0 \\
Chaetozone setosa & 10 & 16 \\
Sep & & \\
Spiophanes bombyx & 4220 & 489 \\
Nucula nitidosa & 308 & 111 \\
Chamelea gallina & 37 & 167 \\
Polydora sp. & 124 & 1 \\
Fabulina fabula & 100 & 164 \\
Abra alba & 14 & 111 \\
Diastylis bradyi & 126 & 24 \\
Spio filicornis & 67 & 38 \\
Ampelisca brevicornis & 82 & 14 \\
Abra sp. (juvenile) & 0 & 65 \\
& & \\
\hline
\end{tabular}

Number of species (S) per $0.1 \mathrm{~m}^{2}$

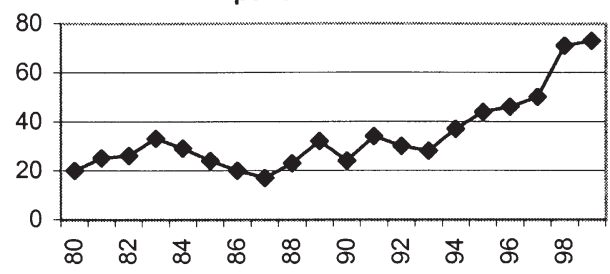

Total abundance (A) per $0.1 \mathrm{~m}^{2}$

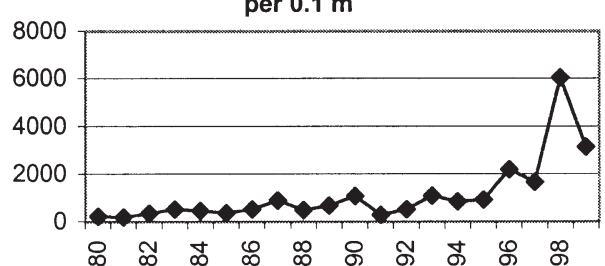

Shannon species diversity ( $H^{\prime}$ using $\log _{\mathrm{e}}$ )

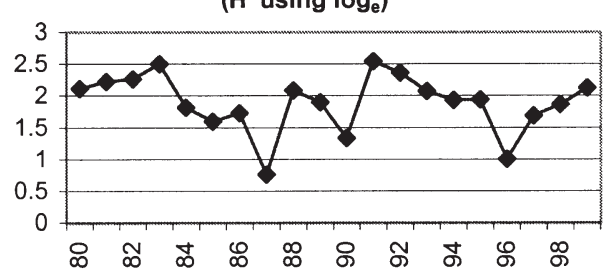

in the outer estuary ( $\rho=0.66$ ) than the inner estuary ( $\rho=0.58)$. When compared to each other, using rank correlation between their respective biological similarity matrices, the 2 areas showed similar patterns of community change $(\rho=0.58)$.

In the outer estuary, there was an increase in the number of species present throughout the sampling period, which steepened from 1994 onwards (Fig. 11). There was also an increase in the number of individuals, which was accentuated in 1998. There were no obvious trends in Shannon diversity $\left(H^{\prime}\right)$. A sudden increase in average taxonomic distinctness $\left(\Delta^{+}\right)$and a decrease in variation in taxonomic distinctness $\left(\Lambda^{+}\right)$ occurred between 1987 and 1988, about the same time as in the Bay, but the direction of change was opposite to that in the Bay. Note, however, that after the step change, $\Delta^{+}$was still higher in the Bay than the estuary: in the estuary, it increased to around 85 and in the Bay it decreased to around $89 . \Lambda^{+}$in the outer estuary and the Bay converged to approximately the same value. The inner estuary also showed an increase in the number of species and in Shannon diversity. The most recent period showing a sustained increase in species coincided with the construction of a tidal barrage, which was completed during 1994 and commissioned in January 1995. There were no obvious trends in the number of individuals,$\Delta^{+}$and $\Lambda^{+}$(Fig. 12).
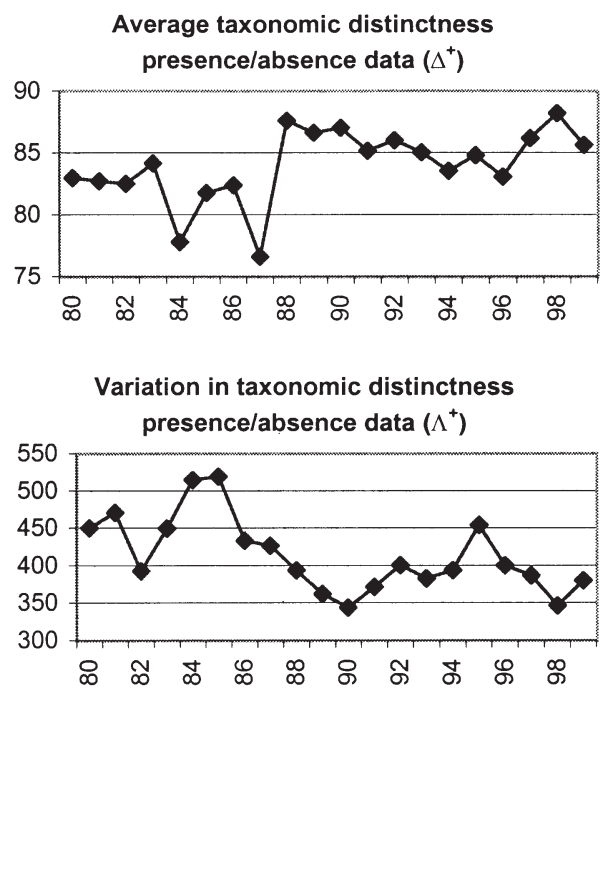

Fig. 11. Times series (1980 to 1999) of univariate indices for Tees estuary macrofauna, from averaged outer estuary samples sampled in September 


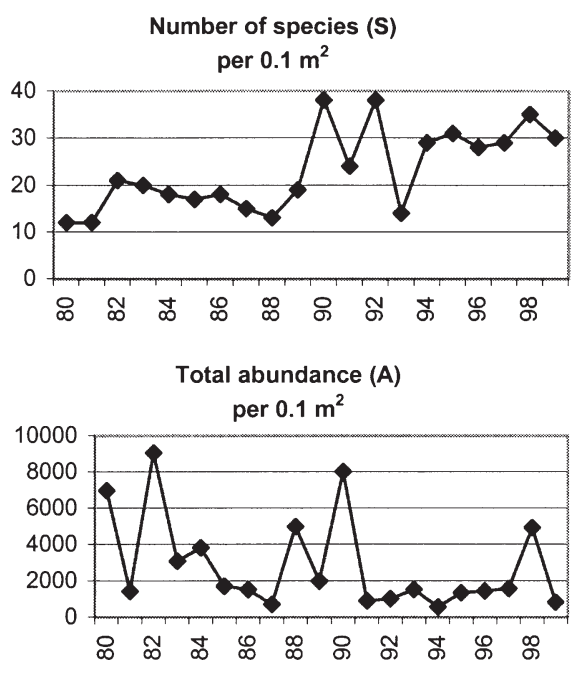

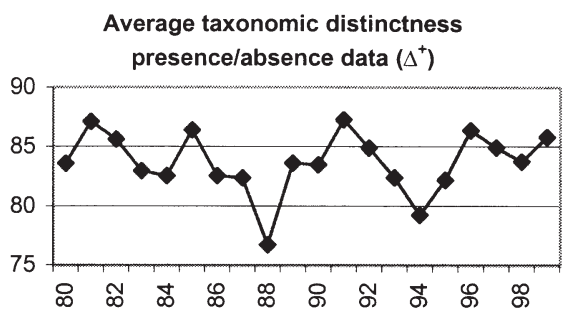

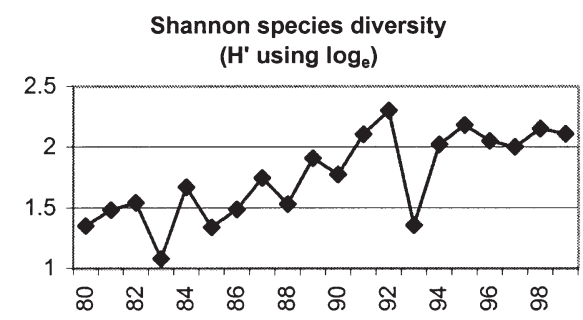

Variation in taxonomic distinctness presence/absence data $\left(\Lambda^{+}\right)$

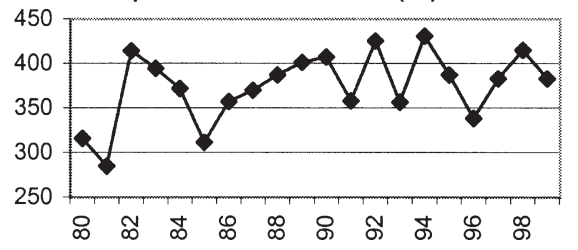

Fig. 12. Times series (1980 to 1999) of univariate indices for Tees estuary macrofauna, from averaged inner estuary samples sampled in September

\section{DISCUSSION AND CONCLUSIONS}

The influences of regional (North Sea-wide) and local (Tees estuary) events are both evident in the observed temporal changes in community structure and composition in Tees Bay and the outer estuary. However, no regional effects were detected in the inner estuary. In the Bay, the ecosystem regime shift was seen in a variety of univariate indices and also in a decrease in community stability in all areas. However, the community response differed between areas close to and distant from the estuary mouth, probably resulting from the effect of outputs from the river. Closer areas had a less stable community composition, interannual changes in composition were less serial in nature, and the average values for a number of univariate indices were lower.

The regime shift had all the symptoms of eutrophication, although its widespread occurrence in the North Sea and beyond suggests otherwise (Reid \& Edwards in press). Traditional measures of biodiversity indicate that this regime shift either had a neutral effect in Tees Bay, e.g. there was no change in species richness, or that it reflected environmental improvement, e.g. there was an increase in $H^{\prime}$. However, the latter increase was due almost entirely to the increase in evenness $\left(J^{\prime}\right)$ resulting from the loss of the overwhelmingly dominant polychaete Spiophanes bombyx. The decrease in average taxonomic spread $\left(\Delta^{+}\right)$and increase in the unevenness of that spread $\left(\Lambda^{+}\right)$can both be regarded as symptoms of environmental deterioration that have already been intuitively recognised in the North Sea (North Sea Task Force 1993), but are only quantifiable, in univariate terms, using these 2 recently developed biodiversity indices. Similarly, the decrease in interannual community stability (MSI) after a relatively stable period prior to the shift can be regarded as a reflection of environmental deterioration. Taxonomic distinctness measures that use quantitative information on abundances of individuals in each species proved to be less useful in detecting this change. Taxonomic diversity $(\Delta)$ is strongly dependent on the species abundance distribution and closely tracked changes in $H^{\prime}$, as has been noted in a number of other studies (e.g. Somerfield et al. 1997, Hall \& Greenstreet 1998). Average taxonomic distinctness based on numbers of individuals rather than numbers of species $\left(\Delta^{*}\right)$ showed no appreciable change over the sampling period, the abundance distribution again masking the change in species composition. $\Delta^{+}$and $\Lambda^{+}$, based on simple presence/absence data (species lists), proved on the other hand to reflect this regime shift very clearly.

The reason for the reversal of the effect of the regime shift on $\Delta^{+}$and $\Lambda^{+}$in the outer estuary remains unclear. However, it could be speculated that the deleterious effects of the regime shift in the Bay, which may have led to increased sedimentation of phytoplankton, decreased oxygen and increased temperature, might be ameliorated for estuarine species that are adapted to wide fluctuations in these variables, and they might respond positively to the increase in productivity. In the outer estuary, $H^{\prime}$ did not change at the time of the regime shift, and also showed no response to changes in community composition and increases in species richness and abundance that occurred after 1994. These latter changes coincided with the final stage of construction of the Tees barrage which involved the building of coffer dams. Although the barrage was not commissioned until January 1995, the temporary coffer dams may have altered the tidal regime by September 1994, when sampling was undertaken. Although the abrupt change in community composition in 1994 was also seen in the inner estuary, gradual increases in $S$ 
and $H^{\prime}$ appear to reflect a general improvement in estuarine quality over the whole sampling period, or a shift to more saline conditions.

Periods of stability and instability have also been reported elsewhere in the North Sea. Buchanan \& Moore (1986) reported a relatively stable period at 2 stations off the coast of Northumberland between 1974 and 1980, followed by a period of change between 1981 and 1983. This is prior to the North Sea regime shift, but the Tees data do reflect these changes to some degree in that a relatively large change in community composition took place between 1982 and 1983, following a previous period of relative stability from 1973 (Fig. 3). Trends of interannual change reported here are particularly clear compared with those of many other studies. This is largely because of the richness of the database and the averaging over large numbers of replicates, sites and areas that eliminates noise due to small-scale spatial variations. It is unfortunate that the collection of data for this time series has now been discontinued following the fragmentation of industry in the area. The changes reported here are shown to be a barometer of the health of the North Sea and adjacent waters, and the evaluation of different indicators of environmental condition suggest the possibility of more cost-effective and environmentally meaningful monitoring. Consideration might usefully be given to future monitoring of a subset of stations in Tees Bay (since they all reflect the same pattern of change) and to compiling simple species lists for these stations rather than the very laborious enumeration of species abundances. These lists could be used to determine indices such as $\Delta^{+}$and $\Lambda^{+}$that have been shown here to be meaningful indicators of biodiversity change. Even if monitoring is not reinstated here, it will be important for the future to ensure that biodiversity indicators other than species richness and evenness measures are incorporated into monitoring programmes generally, since traditional indices have been shown here to be either unhelpful or positively misleading.

Acknowledgements. The macrobenthic monitoring programmes in Tees Bay and the Tees estuary were funded, in part, by ICI, AstraZeneca, ENRON Teesside Operations Limited and Cleveland Potash Limited. The data analyses presented here were funded by the UK Ministry of Agriculture, Fisheries and Food (project no. AE1138).

\section{LITERATURE CITED}

Becker GA, Pauly M (1996) Sea surface temperature changes in the North Sea and their causes. ICES J Mar Sci 53: 887-898

Becker GA, Frohse A, Damm P (1997) The north western
European shelf temperature and salinity variability. Dtsch Hydrogr Z 49:145-161

Buchanan JB, Moore JJ (1986) A broad review of variability and persistence in the Northumberland benthic fauna1971-85. J Mar Biol Assoc UK 66:641-657

Clarke KR, Warwick RM (1998) A taxonomic distinctness index and its statistical properties. J Appl Ecol 35:523-531

Clarke KR, Warwick RM (1999) The taxonomic distinctness measure of biodiversity: weighting of step lengths between hierarchical levels. Mar Ecol Prog Ser 184:21-29

Clarke KR, Warwick RM (2001) A further biodiversity index applicable to species lists: variation in taxonomic distinctness. Mar Ecol Prog Ser 216:265-278

Clarke KR, Warwick RM, Brown BE (1993) An index showing breakdown of seriation, related to disturbance, in a coralreef assemblage. Mar Ecol Prog Ser 102:153-160

Corten A, van de Kamp G (1992) Natural changes in pelagic fish stocks of the North Sea in the 1980s. ICES Mar Symp 195:402-417

Crisp DJ (1984) Energy flow measurements. In: Holme NA, McIntyre AD (eds) Methods for the study of marine benthos, 2nd edn. Blackwell Scientific Publications, Oxford, p 284-372

Dahl E, Danielssen DS (1992) Long term observations of oxygen in the Skagerrak. ICES Mar Sci Symp 195: 455-461

Dickson RR, Turrell WR (2000) The NAO: The dominant atmospheric process affecting oceanic variability in home, middle and distant waters of European salmon. In: Mills D (ed) The ocean life of Atlantic salmon: environmental and biological factors influencing survival. Fishing News Books, Oxford, p 92-115

Ducrotoy JP, Elliott M, De Jonge VN (2000) The North Sea. Mar Pollut Bull 41:5-23

Edwards M, Reid PC, Planque B (2001) Long-term and regional variability of phytoplankton biomass in the northeast Atlantic (1960-1995). ICES J Mar Sci 58:39-49

Hall SJ, Greenstreet SP (1998) Taxonomic distinctness and diversity measures: responses in marine fish communities. Mar Ecol Prog Ser 166:227-229

Hickel W, Eikhoff M, Spindler H, Berg J, Raabe T, Muller R (1996) Auswertungen von Langzeit-Untersuchungen von Nährstoffen und phytoplankton in der Deutschen Bucht. Umweltbundesamt, Berlin

Kröncke I, Dippner JW, Heyen H, Zeiss B (1998) Long-term changes in macrofaunal communities off Norderney (East Frisia, Germany) in relation to climate variability. Mar Ecol Prog Ser 167:25-36

Lewis RE (1990) The nature of outflows from the north-east estuaries. Hydrobiologia 195:1-11

Lewis RE (1992) Models for coastal and estuarine problems: a review of ICI's approach on Teesside. In: Falconer RA, Shiono K, Matthew RGS (eds) Hydraulic and environmental monitoring: estuarine and river waters, Vol 2. Ashgate Publishing, Aldershot, p 265-275

Lewis RE, Riddle AM, Lewis JO (1998) Effect of a tidal barrage on currents and density structure in the Tees estuary. In: Dronkers J, Scheffers M (eds) Physics of estuaries and coastal seas. Balkema, Rotterdam, p 33-38

Lindeboom H, van Raaphorst W, Beukema J, Cadée G, Swennem C (1995) Sudden changes in the North Sea and Wadden Sea: oceanic influences underestimated? Dtsch Hydrogr Z Suppl 2:87-100

North Sea Task Force (1993) North Sea quality status report 1993. Oslo \& Paris Commissions, London. Olsen \& Olsen, Fredensborg

Prandle D, Hydes DJ, Jarvis J, Macmanus J (1997) The sea- 
sonal cycles of temperature, salinity, nutrients and suspended sediments in the southern North Sea in 1988 and 1989. Estuar Coast Shelf Sci 45:669-680

Reid PC, Edwards M (in press) Long-term changes in the pelagos, benthos and fishery, of the North Sea. Senckenb Marit

Reid PC, Borges MDF, Svendsen E (2001a) A regime-shift in the North Sea circa 1988 linked to changes in the North Sea fishery. Fish Res 50:163-171

Reid PC, Holliday NP, Smyth TJ (2001b) Pulses in the eastern margin current and warmer water off the northwest European shelf linked to North Sea ecosystem changes. Mar Ecol Prog Ser 215:283-287

Reise K (1982) Long-term changes in the macrobenthic invertebrate fauna of the Wadden Sea: are polychaetes about to take over? Neth J Sea Res 16:29-36

Shillabeer N (1993) Assessing the effectiveness of quality standards for marine benthos using data from the Tees Bay monitoring programme. In: Eleftheriou A, Ansell AD, Smith CJ (eds) Biology and ecology of shallow coastal waters. Proc 28th Eur Mar Biol Symp. Olsen \& Olsen, Fredensborg

Editorial responsibility: John Gray (Contributing Editor), Oslo, Norway
Shillabeer N , Tapp JF (1990) Long-term studies of the benthic biology of Tees Bay and the Tees estuary. Hydrobiologia 195:63-78

Somerfield PJ, Olsgard F, Carr MR (1997) A further examination of two new taxonomic distinctness measures. Mar Ecol Prog Ser 154:303-306

Vuorinen I, Hanninen J, Viitasalo M, Helminen U, Kuosa H (1998) Proportion of copepod biomass declines with decreasing salinity in the Baltic Sea. ICES J Mar Sci 55: 767-774

Warwick RM, Clarke KR (1993) Increased variability as a symptom of stress in marine communities. J Exp Mar Biol Ecol 172:215-226

Warwick RM, Clarke KR (1995) New 'biodiversity' measures reveal a decrease in taxonomic distinctness with increasing stress. Mar Ecol Prog Ser 129:301-305

Warwick RM, Clarke KR (1998) Taxonomic distinctness and environmental assessment. J Appl Ecol 35:532-543

Warwick RM, Clarke KR (2001) Practical measures of marine biodiversity based on relatedness of species. Oceanogr Mar Biol Annu Rev 39:207-231

Submitted: March 21, 2001; Accepted: November 11, 2001 Proofs received from author(s): May 6, 2002 